\title{
Chlorophyll and carotenoid transformation and destruction by Calanus spp. grazing on diatoms
}

\author{
E. J. H. Head, L. R. Harris \\ Biological Oceanography Division, Bedford Institute of Oceanography, PO Box 1006, Dartmouth, Nova Scotia, \\ Canada B2Y 4A2
}

\begin{abstract}
Copepods and seawater were collected during spring bloom conditions off southwest Nova Scotia and the east coast of Newfoundland, Canada. The copepods were starved for 12 or $24 \mathrm{~h}$ and then fed with screened seawater. High pressure liquid chromatography (HPLC) was used to measure the concentrations of chlorophylls $a$ and $c$ (and derived phaeopigments), fucoxanthin and diadinoxanthin in the incubation medium both before and after grazing, and in purified samples of faecal pellets collected after grazing. Close to $100 \%$ of ingested chlorophylls a and $c$ did not survive digestion by copepods. Virtually no phaeophorbide $a$ or phaeophytin a were produced but instead one or both of their pyrolised derivatives. A pyrolised phaeoporphyrin $c$ derivative was apparently also produced. Fucoxanthin was completely broken down during digestion, but some or all may have been converted to a less polar unidentified derivative. Some ingested diadinoxanthin sometimes appeared intact in faecal pellets. The conversion efficiency of chlorophyll a to pyrophaeopigment a was not usually $100 \%$, but ingested chlorophyll a was less extensively destroyed than either chlorophyll $c$ or diadinoxanthin. The degree of destruction for the 3 pigments varied in parallel and when it was relatively low the only fluorescent components found in faecal pellets, in appreciable amounts, were chlorophylls $a$ and $c$ and the 3 pyrophaeopigments. When the degree of pigment destruction was high, a number of unidentified fluorescent components were also present in faecal pellets, which were probably the products of more extensive chlorophyll degradation.
\end{abstract}

\section{INTRODUCTION}

It has long been known that copepods grazing on phytoplankton convert chlorophyll a into phaeopigments (Currie 1962, Daley 1973). More recently, however, it has been shown that in laboratory feeding experiments this conversion is not always $100 \%$ efficient, so that some proportion of the ingested chlorophyll a sometimes does not appear as phaeopigment, either in copepod guts (Head 1988, Lopez et al. 1988) or in faeces (Conover et al. 1986, Head 1988). The proportion of chlorophyll a destroyed varies depending on the previous long-term (in situ) and short-term (preincubation) feeding history of the copepods (Penry \& Frost 1991, Head 1992), but additional factors, including differences in copepod species or dietary composition and incubation conditions, may also be involved (Head 1992).

In most of the experiments in which pigment destruction has been studied, either by calculating pigment budgets in feeding incubations before and after grazing (Helling \& Baars 1985, Lopez et al. 1988), or by comparing ratios of pigment to an inert tracer in food and faeces (Head 1988, Penry \& Frost 1991), measurements of chlorophyll and phaeopigments have been by the use of a Turner-type fluorometer. Because fluorometers are calibrated using only chlorophyll $a$, all calculations implicitly assume that only chlorophyll $a$ and its breakdown products are present. In fact, however, this is not always the case. For example in addition to chlorophyll $a$, diatoms and dinoflagellates usually contain chlorophyll $c_{1}$ while prasinophytes and chlorophytes often contain chlorophyll $b$ (Rowan 1989a). The presence of chlorophylls $b$ and $c$ and their derivatives causes errors in the perceived estimates of chlorophyll $a$ and 'a-type' phaeopigments (Holm-Hansen et al. 1965, Helling \& Baars 1985) so that degrees of chlorophyll a destruction calculated using Turner fluorometers may have been inaccurate. 
In recent years HPLC techniques have been developed which have enabled the rapid separation, identification and quantification of chlorophyll-type and carotenoid pigments in samples of marine algae and in naturally occurring particulate material (Mantoura \& Llewellyn 1983, Wright \& Shearer 1984, Gieskes \& Kraay 1989). Phaeopigments derived from chlorophyll $a$ have been found in samples from the water column, sediment traps and faecal pellets (Bidigare et al. 1985, Vernet \& Lorenzen 1987, Roy 1989, Roy \& Poulet 1990. Head \& Horne 1992), but quantitative HPLC analysis of chlorophyll a grazing by copepods has been limited so far to a study in which Roy et al. (1989) were looking for evidence of 'sloppy' feeding, by feeding the extremely large diatom Coscinodiscus wailseii to Calanus helgolandicus and Temora longicornis. 'Sloppy' feeding was inferred from the observation that some of the chlorophyll a initially in the $C$. wailseii was transferred to smaller particles during grazing. Overall, however, the decrease in chlorophyll a concentration in C. wailseii was not matched by the sum of the increases in chlorophyll $a$ in small particles, and phaeopigments, either in the copepods' guts or in faeces in the water. Hence chlorophyll a was partly destroyed during grazing in their experiments.

Roy et al. (1989) made no attempt to measure the concentrations of algal carotenoids, to see if they were either more, or less, resistant to digestive breakdown than chlorophyll a. Some unaltered carotenoids have been found in copepod faecal pellets (Nelson 1989) and it has been suggested or assumed that carotenoids are not extensively degraded during passage through copepod guts (Kleppel et al. 1988, 1991).

In this study we used HPLC analysis to measure the concentrations of chlorophyll and carotenoid pigments in feeding experiments before and after grazing by copepods, in order to compare the degrees to which all algal pigments were destroyed. The algal food and copepods were collected during spring bloom conditions, either off southwest Nova Scotia or the east coast of Newfoundland, Canada. We also measured the concentrations of pigments in faecal pellets collected from copepods which had fed in our experimental incubations.

\section{MATERIALS AND METHODS}

Sample collection. Samples of seawater and copepods were collected either in Roseway Basin, off the southwest of Nova Scotia, in April 1991 (43.20' N, $65^{\circ} 10^{\prime} \mathrm{W}$ - Expts 1 to 4 ), or off the east coast of Newfoundland, in May 1991 (48 $30^{\circ} \mathrm{N}, 51^{\circ} 30^{\circ} \mathrm{W}$ - Expt 5; $48^{\circ} 52^{\prime} \mathrm{N}, 52^{\circ} 43^{\prime} \mathrm{W}-$ Expt 6 ). Seawater to feed to copepods was collected using a $30 \mathrm{l}$ Niskin bottle from near the depth of the chlorophyll maximum, which was identified by an in vivo fluorometer in April and was approximated by visual inspection of filters of $100 \mathrm{ml}$. seawater from $10 \mathrm{~m}$ clepth intervals obtained from a CTD rosette in May. Copepods were collected by vertical net tow to $50 \mathrm{~m}$ using a $0.75 \mathrm{~m}$ diameter ring net fitted with a $202 \mu \mathrm{m}$ mesh. After capture copepods were screened through a $3 \mathrm{~mm}$ mesh, to remove large organisms, concentrated and rinsed on a large diameter $505 \mu \mathrm{m}$ screen.

Experimental procedures. There were 4 experiments carried out in April 1991. Experimental procedures were the same for the first three (Expts 1 to 3 ), which were carried out on April 6-7 (Expt 1) and April 8-9 (Expts 2 \& 3). The copepods were collected at midday and starved for between 11 and $1.2 \mathrm{~h}$ by incubating them in $8 \mathrm{l}$ carboys of filtered seawater. These and all other incubations were in the dark in a deck incubator through which surface seawater was running continuously. For experiments in Roseway Basin (Expts 1 to 4 ), the experimental temperature was $5^{\circ} \mathrm{C}$. Seawater containing the microplankton to feed the copepods was collected from a depth of $10 \mathrm{~m}$ at about 20:00 h. At between 23:00 h and midnight the seawater food was screened through a large diameter $102 \mu \mathrm{m}$ screen. For each experiment a 20 l polycarbonate experimental bottle, to which copepods would be added, was filled with screened water to within $500 \mathrm{ml}$ of capacity. An 81 control bottle, to which no copepods would be added, was also filled. Copepods were concentrated on a $780 \mu \mathrm{m}$ screen and rinsed with filtered seawater, just before being added to the experimental bottle. Immediately after addition of the copepods, the 20 I bottle was inverted several times and a 2 l subsample was taken. This was screened through a $505 \mu \mathrm{m}$ mesh to remove the copepods, which were rinsed, collected on sharkskin filters and frozen for gut pigment analysis (Turner fluorometer only). Subsamples of screened water (250 or $500 \mathrm{ml}$ ) were filtered on to GFF glass fiber filters. Control bottles were subsampled in the same way. Filters were frozen and stored in liquid nitrogen for subsequent pigment analysis by HPLC. Experimental and control bottles were subsampled as before, after incubation periods of between 6.5 and $7.5 \mathrm{~h}$. A 11 sample was also taken from the experimental bottle for copepod enumeration and species identification. Faecal pellets were col. lected from the $15 \mathrm{l}$ of seawater remaining in the experimental bottle by reverse filtration through a large diameter $102 \mu \mathrm{m}$ mesh, followed by collection on a $202 \mu \mathrm{m}$ mesh.

Expt 4 was carried out in Roseway Basin on April 18-19. For this experiment the procedure described above was followed, except that the seawater microplankton was collected from a depth of $20 \mathrm{~m}$ and that 
samples for HPLC analysis were taken only at the end of the incubation and then only for water from the control bottle and for faecal pellets from the experimental bottle.

In May 1991, the feeding experiments were similar to Expts 1 to 3 . The water was again collected from a depth of $10 \mathrm{~m}$. Both water and copepods were prescreened in the same way, and initial and final subsamples were also taken in the same way. In these experiments, however, the copepods were starved for either $12 \mathrm{~h}$ (Expts 5a \& 6a) or $24 \mathrm{~h}$ (Expts 5b \& 6b) before being fed and there were 2 experimental bottles and 1 control bottle in each case (except Expt 5a, where there was only 1 experimental bottle). Faecal pellets were collected from 1 experimental bottle per experiment. Further differences were that samples for pigment analysis were filtered on to GFC glass fiber filters and that the experimental food (i.e. seawater) and copepods were collected at the same time. For Expt 5 (April 18-19), water and copepods were collected at midday. For Expt 6 (April 19-21), they were collected at about $22: 00 \mathrm{~h}$. For Expts $5 \& 6$ the incubation temperature was $-0.5^{\circ} \mathrm{C}$.

Analysis of samples. Measurement of the concentrations of chlorophyll and phaeopigments in copepod guts, using a Turner fluorometer, was as in Head (1992). HPLC identification and quantification of pigments, using known standards, was based on the method of Gieskes \& Kraay (1989) modified as described by Head \& Horne (1992). Carotenoid and chlorophyll a concentrations were determined from absorbance chromatograms. The other fluorescent pigments were quantified from fluorescence chromatograms, unless their concentrations exceeded the detection range of the fluorometer, when the absorbance chromatograms were used. All phaeopigments are expressed as the chlorophyll equivalent weights of the chlorophylls from which they were derived.

\section{RESULTS AND DISCUSSION}

\section{Pigment composition of seawater and faecal pellets}

Ungrazed seawater samples had a similar relatively simple pigment composition in all of the incubation experiments (Fig. 1, Table 1). Of the fluorescent pigments, chlorophyll a (plus its allomer) was the most abundant (50 to $58 \%$ total pigment) and chlorophyll $c$ $\left(c_{1}+c_{2}\right)$ was the next most abundant $(7$ to $12 \%$ total pigment). Fucoxanthin was the most concentrated carotenoid (19 to $29 \%$ total pigment) and diadinoxanthin was the next most ( 2 to $5 \%$ total pigment). These pigments, along with beta-carotene, which was present at lower levels ( $<2 \%$ total pigment), are all
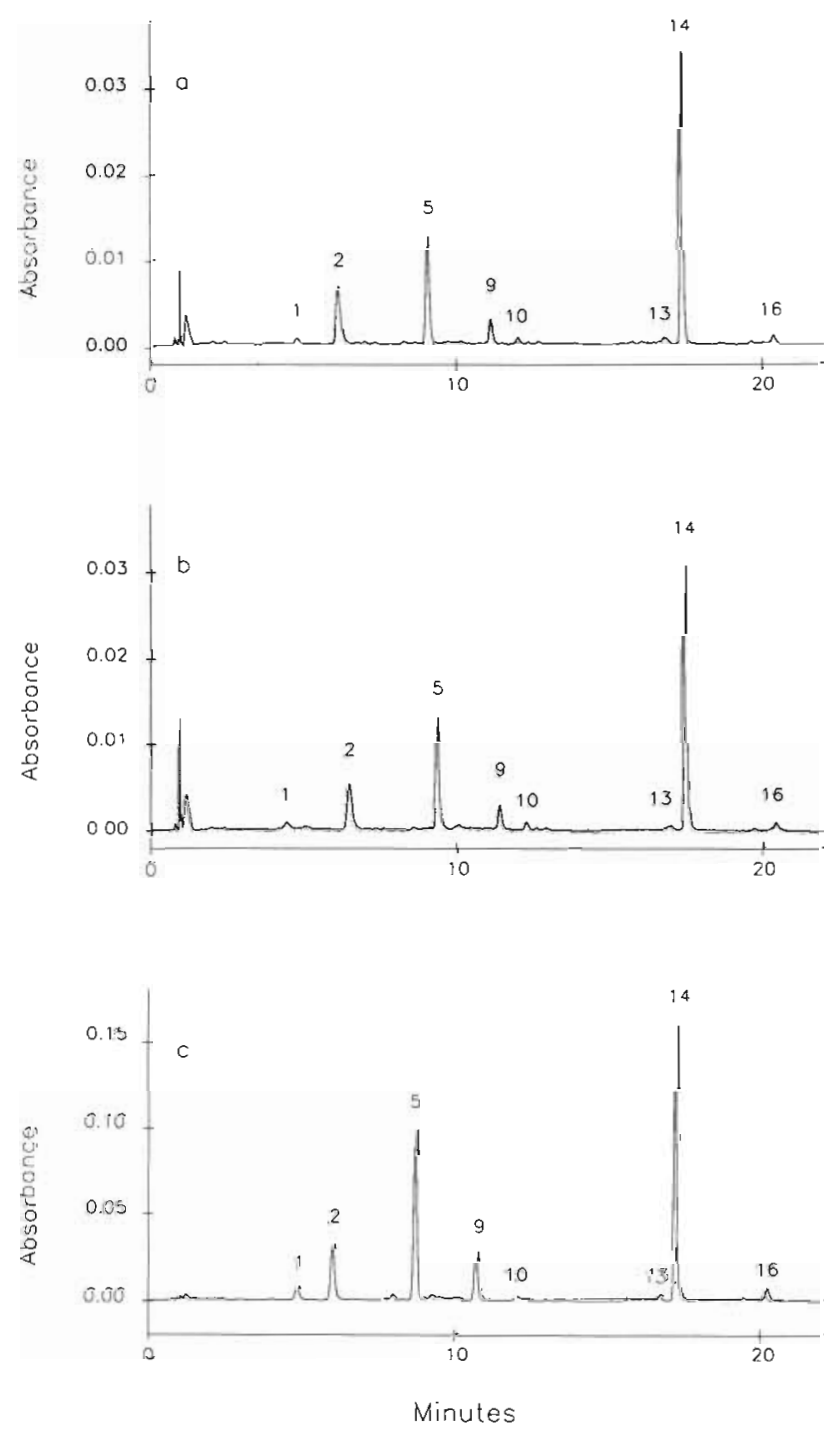

Fig. 1. Absorbance chromatograms of screened seawater collected (a) in Roseway Basin on April 8, 1991; (b) in Roseway Basin on April 18, 1991; (c) off the coast of Newfoundland on May 20, 1991. Pigment identifications: (1) chlorophyllide a: (2) chlorophyll $c_{\text {; }}$ (3) unknown phaeophorbide a-like P2; (4) unknown phaeophorbide a-like P3; (5) fucoxanthin; (6) pyrophaeophorbide $a_{;}(7)$ unknown carotenoid $\mathrm{C} 1 ;(8)$ pyrophaeopophyrin c-like; (9) diadinoxanthin; (10) diatoxanthin; (11) unknown phaeophorbide $a$-like P4; (12) chlorophyll $b$; (13) chlorophyll $a$ allomer; (14) chlorophyll $a$; (15) phaeophytin $a_{;}$(16) $\beta$-carotene; (17) pyrophaeopytin $a$

characteristic of diatoms (Rowan 1989b), visually the dominant phytoplankton.

Chlorophyllide a, which was always less than $3 \%$ of the total pigment, may have been produced artifactually during sample preparation by the action of chlorophyllase present in the algae (Jeffrey \& Hallegraeff 1987). Chlorophyllide $a$ is included with chlorophyll a in calculations of chlorophyll + phaeopigment a budgets. 
Table 1. Percentage pigment composition of seawater in control bottles. Percentages are rounded up to whole numbers and pigments present at $<0.5 \%$ of the total are not included. Detection limits were of the order of 15 ng $\mathrm{l}^{-1}$ for fluorescent pigments

\begin{tabular}{|c|c|c|c|c|c|c|c|c|c|c|c|}
\hline $\begin{array}{l}\overrightarrow{\vec{a}} \\
\vec{x}\end{array}$ & 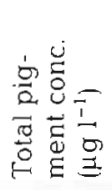 & 웅 & $\begin{array}{l}\bar{v} \\
+ \\
\bar{u} \\
u \\
\vec{U}\end{array}$ & 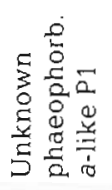 & 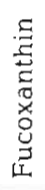 & 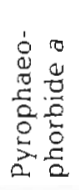 & 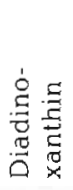 & $\frac{a}{\mathcal{L}}$ & 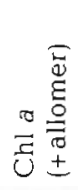 & $\begin{array}{l}0 \\
0 \\
0 \\
0 \\
0 \\
0 \\
0 \\
0\end{array}$ & $\stackrel{\stackrel{⿹}{\Xi}}{\overrightarrow{0}}$ \\
\hline 1 & 5.9 & 2 & 11 & 4 & 23 & 0 & 3 & 2 & 50 & 1 & 2 \\
\hline 2 & 3.5 & 2 & 11 & 5 & 19 & 0 & 3 & 2 & 56 & 1 & 1 \\
\hline 3 & 3.6 & 2 & 12 & 5 & 19 & 0 & 2 & 2 & 55 & 1 & 3 \\
\hline 4 & 3.1 & 1 & 10 & 2 & 23 & 0 & 3 & 1 & 58 & 0 & 2 \\
\hline $5 a$ & 24.5 & 2 & 8 & 1 & 28 & 0 & 4 & 1 & 54 & 1 & 0 \\
\hline $5 b$ & 20.7 & 1 & 7 & 0 & 29 & 1 & 4 & 1 & 55 & 1 & 1 \\
\hline 6a & 33.7 & 3 & 8 & 1 & 29 & 1 & 5 & 0 & 52 & 1 & 1 \\
\hline $6 b$ & 20.5 & 2 & 8 & 0 & 28 & 1 & 4 & 1 & 55 & 1 & 1 \\
\hline
\end{tabular}

Chlorophyll $b$, which is not found in diatoms, was also present in the algal food, but it never accounted for more than $2 \%$ of the total pigment concentration. An unknown fluorescent compound ( $\mathrm{P} 1$, not seen in absorbance chromatograms), quantified as if it were an a-type phaeophorbide, was present in samples from Roseway Basin ( 4 to $5 \%$ total pigment), but was nearly absent in samples from off the coast of Newfoundland.

The most concentrated pigment in faecal pellets was pyrophaeophorbide a (44 to $71 \%$ total identified pigment; Figs. 2 \& 3, Table 2). It was identified by comparison of its retention time with that of a standard (provided by Dr D. Repeta) and by its spectrum, and quantified by assuming it to have the same extinction coefficient ( 667 nm) as phaeophytin a. Pyrophaeophorbide $a$ is structurally identical to phaeophorbide $a_{1}$ except for the elimination of a methylated carboxyl group from the isocyclic ring derived from the $\mathrm{C}-13$ propionic acid group. Pyrophaeophytin a, identified by its spectrum and the position at which it ran, was present at a concentration of between about one-fifth and one-half of that of pyrophaeophorbide $a$ in Expts 1, 2, 3, 5 \& 6. By contrast, it was present in only trace amounts $(<1 \%$ of total pigment) in faecal pellets collected in Expt 4 (Table 2, Fig. 2). Structurally, pyrophaeophytin $a$ is pyrolised phaeophytin $a$, in the same way that pyrophaeophorbide $a$ is pyrolised phaeophorbide a. Together these pyrophaeopigments accounted for more than $70 \%$ of the total identifiable pigment in all experiments, except in Expt 4.

After the a-type pyrophaeopigments, the next most important phaeophorbide-like compound was usually one which eluted a little after pyrophaeophorbide a (Figs. 2 \& 3). For some samples, spectra were obtained for this peak which were similar to that of phaeoporphyrin $c$ (the acidification product of chlorophyll $c$ ). Since chlorophyll $a$ and its derivatives are pyrolised in copepod guts, it seems plausible that chlorophyll $c$ may be as well. Phaeophorbide $a$ and the 2 forms of phaeoporphyrin $c\left(c_{1}\right.$ and $C_{2}$ ) have similar retention times in this HPLC system. Hence it seems likely that their

Table 2. Percentage pigment composition of faecal pellets, collected from grazing experiments. Percentages are rounded up to whole numbers and pigments present at concentrations of $<0.5 \%$ of the total are not included. Detection limits were of the order of $0.5 \mathrm{ng}$ for fluorescent pigments and $2 \mathrm{ng}$ for non-fluorescent pigments

\begin{tabular}{|c|c|c|c|c|c|c|c|c|c|c|c|c|c|c|}
\hline $\begin{array}{l}\bar{\alpha} \\
\text { xy }\end{array}$ & 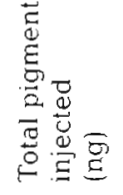 & 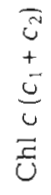 & 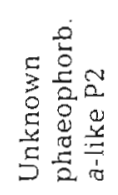 & 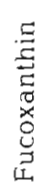 & $\begin{array}{ll}1 & 0 \\
0 & 0 \\
0 & 0 \\
2 & 0 \\
0 & 0 \\
0 & 0 \\
0 & 0 \\
& 0 \\
2 & 0\end{array}$ & 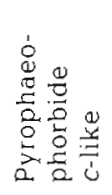 & 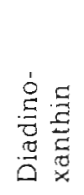 & 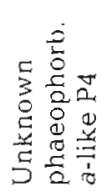 & $\frac{\theta}{E}$ & 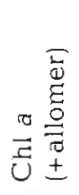 & $\begin{array}{ll} & \pi \\
0 & \Xi \\
0 & \Xi \\
0 & \vdots \\
0 & \frac{Z}{2}\end{array}$ & 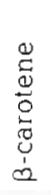 & 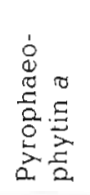 & $\frac{\breve{g}}{\stackrel{\Xi}{0}}$ \\
\hline 1 & 7.5 & 0 & 0 & 0 & 71 & 0 & 0 & 0 & 0 & 13 & 0 & 0 & 16 & 0 \\
\hline 2 & 108.8 & 1 & 4 & 0 & 60 & 5 & 2 & 10 & 0 & 4 & 3 & 0 & 12 & 0 \\
\hline 3 & \multicolumn{14}{|c|}{ No faecal pellets collected } \\
\hline 4 & 15.0 & 1 & 6 & 0 & 44 & 6 & 0 & 13 & 6 & 23 & 0 & 0 & 0 & 0 \\
\hline $5 \mathrm{a}$ & 88.8 & 1 & 1 & 3 & 53 & 4 & 3 & 1 & 0 & 7 & 2 & 0 & 25 & 1 \\
\hline $5 b$ & 306.3 & 0 & 1 & 2 & 56 & 3 & 4 & 0 & 0 & 7 & 0 & 1 & 23 & 2 \\
\hline $6 a$ & 523.3 & 0 & 1 & 1. & 63 & 5 & 7 & 1 & 0 & 3 & 1 & 1 & 17 & 0 \\
\hline $6 b$ & 671.8 & 1. & 1 & 2 & 60 & 4 & 5 & 0 & 0 & 5 & 1 & 0 & 20 & 3 \\
\hline
\end{tabular}



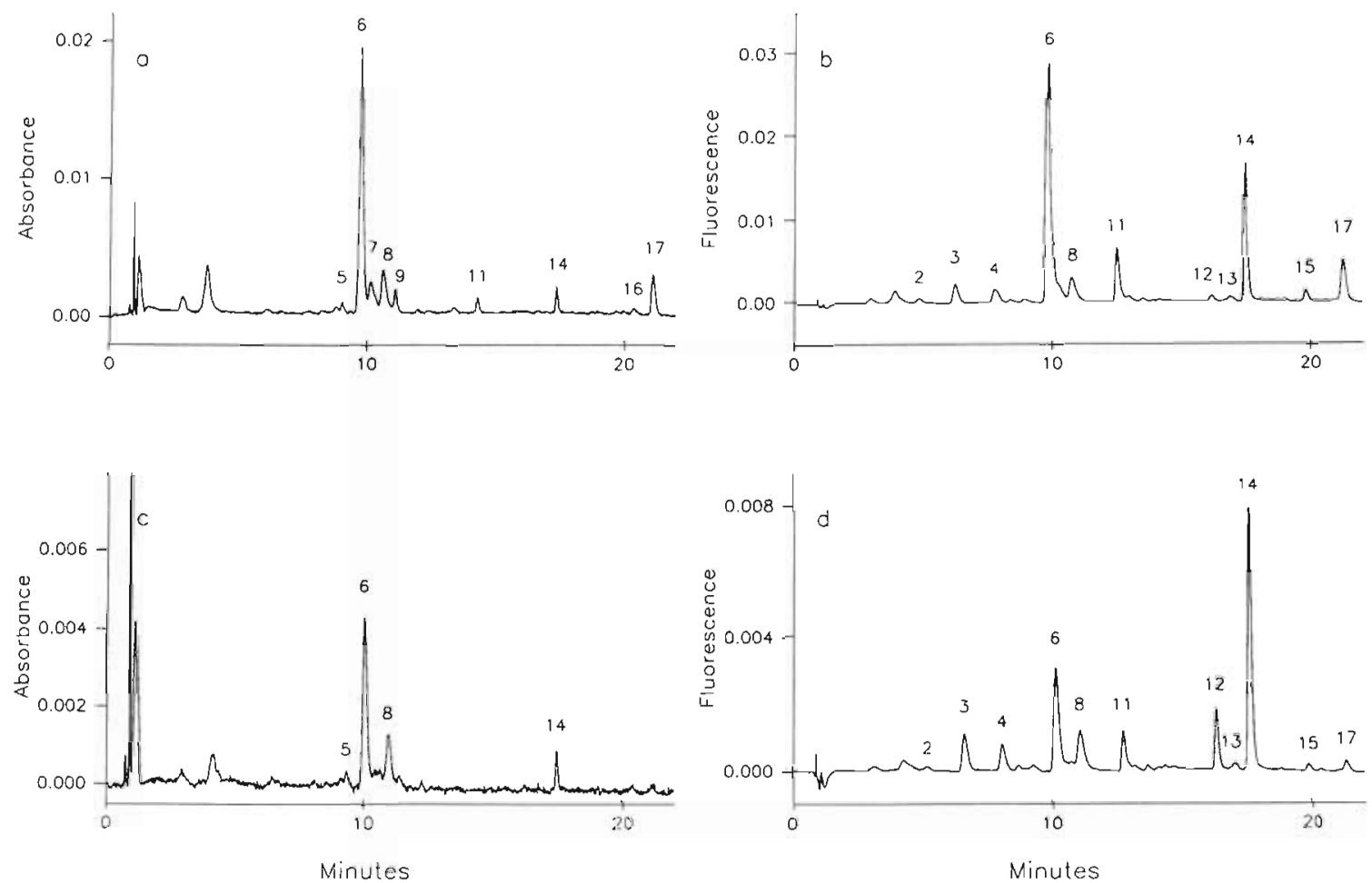

Fig. 2. Absorbance $(a, c)$ and fluoresence (b, d) chromatograms of samples of faecal pellets from Expts 2 (a, b) and 4 (c, d). Pigment identifications as in Fig. 1
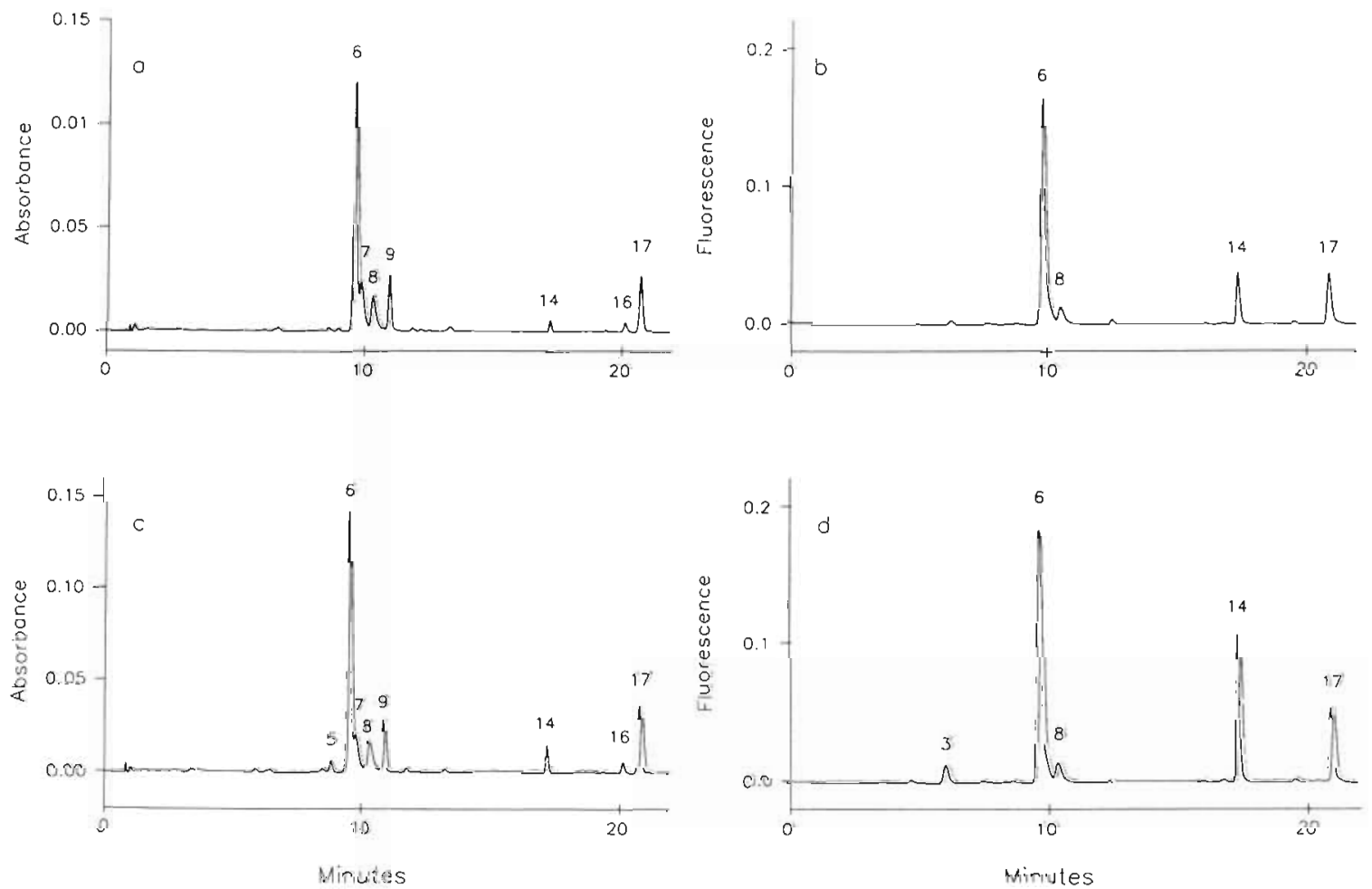

Fig. 3. Absorbance $(a, c)$ and fluorescence $(b, d)$ chromatograms of samples of faecal pellets from Expts $6 a(a, b)$ and $6 b(c, d)$ Pigment identifications as in Fig. 1 
pyrolised derivatives should also. Thus, because of its retention time and its spectrum, this compound has been designated as 'pyrophaeoporphyrin c-like' and quantified using the calibration factor for acidified chlorophyll $c$. As well as these phaeopigments, samples of faecal pellets from experiments in Roseway Basin showed a variety of minor fluorescent peaks (Fig. 2). Two were more polar than chlorophyll $c$, and have not been included in this analysis, because they were probably not phaeopigments. When the others were quantified as if phaeophorbide a-like, only 2 (Fig. $2 ;$ P2 \& P4) accounted for more than $1 \%$ of the total identified pigment (Table 2).

The concentration of fucoxanthin in faecal pellets was generally very low (Table 2). The concentration of diadinoxanthin, when detectable, was higher than that of fucoxanthin, although in algal food the reverse was true (Table 1). In addition to the identifiable carotenoids, there was a non-fluorescent peak in the absorbance chromatogram of most samples which eluted just after pyrophaeophorbide a (Figs. $2 \& 3 ; \mathrm{C} 1$ ). Because fucoxanthin was often absent from faecal pellets while very abundant in algae, and because this unidentified peak did not occur in algae but was generally present in faecal pellets, it is tempting to suggest that it is a digestive breakdown product of fucoxanthin. The peak was not well resolved from pyrophaeophorbide $a$, however, and because its identity is unknown it could not be quantified or used in calculations of pigment budgets.

The low levels of algal chlorophylls and fucoxanthin (when detected) in samples of faecal pellets may have been present because some ingested pigment was not degraded, or because there were intact algae included in the faecal pellets themselves (Bathmann \& Liebezeit 1986), or because there was slight contamination with intact diatom chains (Fig. 4).

\section{Copepod species composition}

In all experiments the copepod population was dominated by Calanus spp. (>99\%). In Expts 1 to 3, C. finmarchicus constituted 60 to $80 \%$ of the population numerically. The other 20 to $40 \%$ were made up of approximately equal numbers of $C$. glacialis and $C$. hyperboreus. In Expt 4, C. finmarchicus accounted for about $40 \%$ of the copepods, C. glacialis about $10 \%$ and C. hyperboreus about $50 \%$. In Expts $5 \& 6, C$. finmarchicus made up about $65 \%$ of the population, $C$. glacialis about $30 \%$ and C. hyperboreus about $5 \%$. Most $C$. finmarchicus and $C$. glacialis were either female or stage $\mathrm{V}$ in all experiments ( $>85 \%$ of either species). Most C. hyperboreus were stage III in Expts 1 to 4 , or stage $V$ in Expts $5 \& 6$.

\section{Pigment budgets in grazing experiments}

The initial concentration of chlorophyll a (and all other pigments) in the experimental bottle was similar to that in the control bottle in each of Expts 1,2 \& 3. In Expts $5 \& 6$, however, there were sometimes quite large differences between bottles (Table 3). For Expts 1 to 3,1 Niskin bottle cast provided enough water for each pair (experimental + control) of incubations. For Expts $5 \& 6$, however, 4 bottle casts were needed to fill the 6 bottles. The samples from the 4 casts (total 120 l) were not mixed prior to setting up the incubations. Thus differences between initial concentrations were most likely because of variations in depths of bottle casts relative to that of the chlorophyll maximum. For this reason we have presented changes in pigment concentrations during incubations on a percentage basis (Table 3 ).

Budgets were only calculated for the concentrations of the 4 major pigments and their identifiable derivatives (chlorophyll $a$, pyrophaeophorbide $a$, pyrophaeophytin $a$, chlorophyll $c$, pyrophaeoporphyrin c-like, fucoxanthin and diadinoxanthin). In control bottles the concentrations of chlorophylls $a$ and $c$ and the carotenoids either increased by up to $18 \%$ or decreased by up to $22 \%$ (Table 3 ). The changes were usually rather less than this, however, and in a pair of pseudo-replicate experiments (Expts $2 \& 3$ ) they were inconsistent, decreasing by about $12 \%$ in one case and increasing by about $2 \%$ in the other. All 4 always varied more or less in parallel and the differences may represent experimental sampling errors. The results from controls were not used in the budget calculations in experimental bottles.

The concentrations of chlorophyll $a_{\text {, chlorophyll } C}$ and fucoxanthin decreased substantially (range 38 to $73 \%$ ) in each of the experimental bottles. Decreases in diadinoxanthin were often proportionally less than those of the other 3 major pigments, especially in Expts $5 \& 6$. Increases in the concentrations of the pyrophaeopigments did not match the decreases in concentrations of the chlorophylls

The concentrations of pigment in copepod guts must be included in order to complete the pigment inventories before and after grazing. Because of the low levels of material available, HPLC analysis was not done and measurements of chlorophyll + phaeopigment $a$ in copepod guts were made using a Turner fluorometer. These may be less susceptible to error than Turner estimates of concentrations of chlorophyll + phaeopigment $a$ in seawater because the fluorescent pigment content of copepod guts resembles the fluorescent pigment content of faecal pellets (Head unpubl.), so that the a-type pyrophaeopigments would have dominated and other fluorescent pigments should 


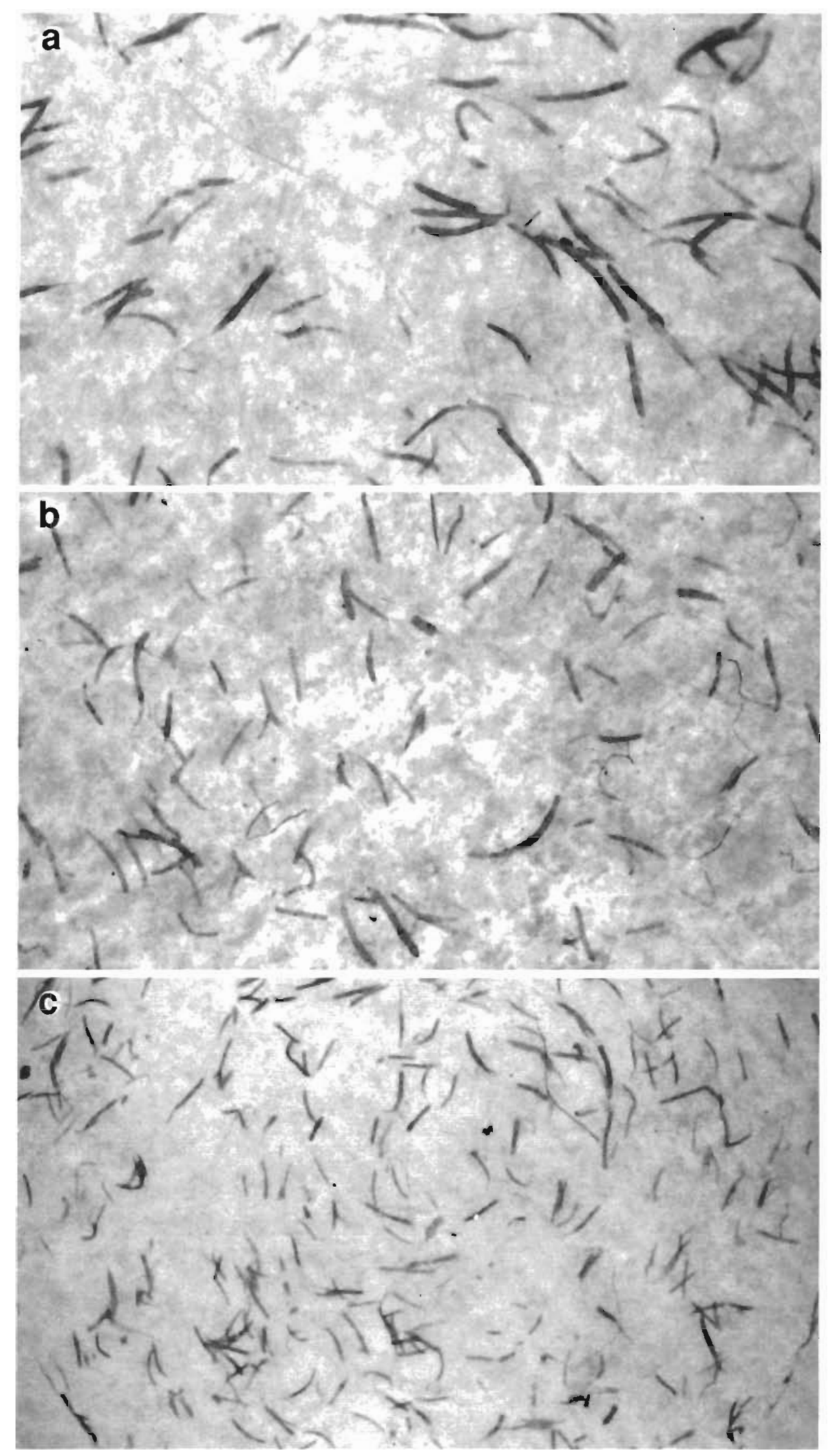

Fig. 4. Samples of faecal pellets from Expts 1 (a) 4 (b) and 5 (c) on glass fiber filters. In all experiments faecal pellets ranged between 0.5 and $1.5 \mathrm{~mm}$ in length (approximately) 
have been relatively scarce (Table 2). The a-type pyrophaeopigments are fluorometrically (and spectrophotmetrically) identical to phaeophytin $a$, which was used to calibrate the fluorometer. Estimated thus, chlorophyll + phaeopigment a concentrations in copepod guts were always less than $1 \mathrm{ng}$ average ind.$^{-1}$ at the start of each incubation and were between $<1$ and $7.5 \mathrm{ng}$ average ind ${ }^{-1}$ at the end. The initial and final pigment concentrations per litre in copepod guts were calculated as the products of the average individual gut pigment concentrations and the copepod concentrations. These were always less than $5 \%$ of the concentration of chlorophyll + phaeopigment a in the water. The pigment contents of copepod guts were therefore ignored in budget calculations.

The degree of chlorophyll a destruction was calculated as the percentage of the sum of chlorophyll a (+ allomer) and chlorophyllide a which disappeared in the experimental bottles (i.e. was grazed), which did not appear in the water as pyrophaeophorbide $a$ or pyrophaeophytin a. Note that the contribution of any undegraded chlorophyll a that did pass into faecal pellets (Table 2) would have been insignificant in the overall budget $k 3 \%$ total chlorophyll + phaeopig- ment a). The degree of chlorophyll a destruction varied between 9 and $82 \%$ (Table 3 ). The degree of chlorophyli $c$ destruction was calculated similarily, as the percentage of grazed chlorophyll $c$ which did not appear as the suggested pyrophaeoporphyrin c-like product. It varied in the range 70 to $100 \%$, apparently in parallel with the degree of chlorophyll a destruction (Table 3).

The degree of fucoxanthin destruction might have been calculated as the proportion not appearing in the unidentified peak C1 (Figs. $2 \& 3$ ), if we had been able to quantify it. As it is, all we can say is that close to $100 \%$ of ingested fucoxanthin was broken down, as evidenced by its percentage decrease in concentration in the incubations relative to those of chlorophyll $a$ and chlorophyll $c$ (Table 3), and its near absence from faecal pellets (Table 2).

The concentration of diadinoxanthin often did not decrease by as large a percentage as did those of the other 3 pigments (Table 3 ). In addition it was sometimes present in faecal pellets (Table 2). If we assume that diadinoxanthin had no immediate conversion product, but that some proportion passed into faecal pellets intact, then the degree of diadinoxanthin

Table 3. Pigment budgets in grazing experiments

\begin{tabular}{|c|c|c|c|c|c|c|c|c|c|}
\hline Expt & $\begin{array}{l}\text { Conc. } \\
\text { of } \\
\text { copepods } \\
\left.\text { (ind }{ }^{-1}\right)\end{array}$ & $\begin{array}{l}\text { Initial } \\
\text { chl } a \\
\text { conc. } \\
\left(\mu \mathrm{g} \mathrm{l}^{-1}\right)\end{array}$ & $\begin{array}{l}\text { Change } \\
\text { in chl } a \\
\text { conc. } \\
(\%)\end{array}$ & $\begin{array}{c}\text { Degree of } \\
\text { chl a } \\
\text { destruction } \\
(\%)\end{array}$ & $\begin{array}{c}\text { Change } \\
\text { in chl } c \\
\text { conc. } \\
(\%)\end{array}$ & $\begin{array}{c}\text { Degree of } \\
\text { chl } c \\
\text { destruction } \\
(\%)\end{array}$ & $\begin{array}{c}\text { Change in } \\
\text { fucoxanthin } \\
\text { conc. } \\
(\%)\end{array}$ & $\begin{array}{l}\text { Change in } \\
\text { diadinoxanthin } \\
\text { conc. } \\
(\%)\end{array}$ & $\begin{array}{c}\text { Degree of } \\
\text { diadinoxanthin } \\
\text { destruction } \\
(\%)\end{array}$ \\
\hline \multicolumn{10}{|l|}{ Expt 1} \\
\hline Control & & 3.07 & 16.4 & & 8.2 & & 14.8 & 6.6 & \\
\hline Experimental & 39 & 2.69 & -64.1 & 79.3 & -66.7 & 100.0 & -62.5 & -63.5 & 95.2 \\
\hline \multicolumn{10}{|l|}{ Expt 2} \\
\hline Control & & 2.05 & -12.2 & & -12.3 & & -13.9 & -18.2 & \\
\hline Experimental & 46 & 2.06 & -65.5 & 81.7 & -71.6 & 100.0 & -66.7 & -62.1 & 86.8 \\
\hline \multicolumn{10}{|l|}{ Expt 3} \\
\hline Control & & 2.07 & 2.4 & & -6.4 & & 3.9 & 6.1 & \\
\hline Experimental & 49 & 2.11 & -62.1 & 74.4 & -70.4 & 100.0 & -63.8 & -60.9 & 86.6 \\
\hline \multicolumn{10}{|l|}{ Expt $5 a$} \\
\hline Control & & 13.72 & 0.9 & & 0.3 & & 2.8 & 1.6 & \\
\hline Experimental & 37 & 10.49 & -40.8 & 64.7 & -49.3 & 95.4 & -45.6 & -37.2 & 75.5 \\
\hline \multicolumn{10}{|l|}{ Expt 5b } \\
\hline Control & & 11.67 & 8.0 & & 10.3 & & 10.4 & 17.7 & \\
\hline Experimental & 27 & 8.86 & -42.4 & 33.0 & -45.6 & 77.2 & -47.0 & -22.1 & 48.5 \\
\hline Experimental & 30 & 12.98 & -38.7 & 29.5 & -45.1 & 78.3 & -45.8 & -25.5 & 56.7 \\
\hline \multicolumn{10}{|l|}{ Expt 6a } \\
\hline Control & & 18.36 & -12.7 & & -6.7 & & -17.4 & -22.0 & \\
\hline Experimental & 27 & 8.52 & -55.1 & 43.6 & -64.8 & 80.4 & -58.6 & -31.3 & 48.3 \\
\hline Experimental & 33 & 10.15 & -59.3 & 48.9 & -66.3 & 82.2 & -63.8 & -39.6 & 59.8 \\
\hline \multicolumn{10}{|l|}{ Expt $6 b$} \\
\hline Control & & 11.52 & -2.6 & & -3.3 & & $0-4$ & -4.3 & \\
\hline Experimental & 29 & 11.37 & -40.9 & 34.6 & -43.0 & 78.3 & -39.0 & -17.5 & 40.7 \\
\hline Experimental & 32 & 11.30 & -69.8 & 9.0 & -72.8 & 70.9 & -73.7 & $-27,4$ & 37.6 \\
\hline
\end{tabular}


destruction can be calculated by comparing its percentage decrease in concentration with those of the other pigments (Table 3). For these calculations chlorophyll $c$ was chosen as the measure of grazing because it may have been the least conservative of the pigments since it always constituted only $1 \%$ or less of the total pigment in faecal pellets (Table 2). The results suggest that the degree of destruction of diadinoxanthin varied in parallel with those of the chlorophylls.

\section{Variability in degree of chlorophyll a destruction and possible causes}

Highly variable degrees of chlorophyll a destruction have often been recorded (Head 1988, Lopez et al. 1988). Here, despite the fact that sampling errors may have been as as high as $\pm 20 \%$, there was actually some continuity in the results (Table 3 ). Thus the degree of chlorophyll a destruction by copepods was high in Roseway Basin after $12 \mathrm{~h}$ starvation prior to feeding ( 75 to $82 \%$ ), lower off Newfoundland after 12 h starvation ( 44 to $65 \%$ ) and lowest off Newfoundland after $24 \mathrm{~h}$ starvation ( 9 to $35 \%$ ). In addition faecal pellets from grazing experiments in Roseway Basin contained more unidentifiable fluorescent products than did those from experiments off Newfoundland, which might also indicate more extensive degradation of the chlorophylls at this site.

Penry \& Frost (1991) and Head (1992) have suggested that copepods which have fed well for an extended period in situ (e.g. late spring bloom conditions) prior to feeding in the laboratory may subsequently destroy more chlorophyll a than do those which have fed over a relatively short period in situ (e.g. early spring bloom conditions). Head (1992) also found that in feeding experiments copepods seem to destroy chlorophyll a to about the same degree as they do in situ if they have been previously starved for $12 \mathrm{~h}$, but destroy less or none if starved for $24 \mathrm{~h}$. Thus, the differences in the degree of chlorophyll a destruction can be explained by differences in previous feeding history if copepods off Newfoundland had been feeding in situ less well for a shorter period than those in Roseway Basin. In fact it is quite possible that the spring bloom had started later off Newfoundland than in Roseway Basin, because there was extensive ice cover in that area in May 1991, with surface temperatures of $<-0.5^{\circ} \mathrm{C}$, whereas in Roseway Basin there had been no ice cover and surface temperatures were at least $1.5^{\circ} \mathrm{C}$.

An alternative explanation for the higher degree of destruction in Expts 1 to 3 vs Expts 5a \& 6a might have been that final concentrations of algae were much lower in the Roseway Basin incubations and that cope- pods re-ingested faecal pellets as food became scarce. We do not believe this, however, because the large faecal pellets would probably have sunk out during the incubations and thus been unavailable for ingestion, and in addition these Calanus species do not readily consume their own faecal pellets (R. J. Conover pers. comm.).

Expt 4 was carried out 10 to $12 \mathrm{~d}$ after Expts 1 to 3 but in the same area (Roseway Basin). In situ conditions would thus probably have been at later stage of the spring bloom and the degree of chlorophyll a destruction might perhaps have been even higher than in Expts 1 to 3 (Penry \& Frost 1991, Head 1992). Although no pigment budget was done for this experiment, there was a notable difference in the identifed pigment content of the faecal pellets, compared with those collected in the other experiments; namely that pyrophaeophytin a was virtually absent (Table 2, Fig. 2). Pyrophaeophytin $a$ is a 'less degraded' breakdown product of chlorophyll a than pyrophaeophorbide $a$, and may be its precursor. Hence the faecal pellets produced in Expt 4 contained the more highly degraded a-type pyrophaeopigment, suggesting more extensive pigment degradation, and hence perhaps a higher degree of pigment destruction. In addition the concentrations of the unidentified breakdown products ( $\mathrm{P} 2$ and $\mathrm{P} 4$ ) were higher relative to pyrophaeophorbide $a$ in faecal pellets collected in Expt 4 than in those collected in Expts 1 \& 2, further supporting the idea of more extensive chlorophyll a degradation. In apparent contradiction, however, faecal pellets from Expt 4 also contained relatively more chlorophyll a than did those from Expts $1 \& 2$ (Table 2). There is no contradiction, however, if the faecal pellets in Expt 4 contained less total pigment. Then the level of chlorophyll a per pellet, or the number of intact algae per pellet, or the level of contamination of pellets with algae, might have been the same as in the other experiments, while the levels of pyrophaeophorbide $a$ and the other breakdown products were lower. An alternative explanation, which cannot be ruled out, is that different copepod species process pigments differently, so that the difference in end products was due to the difference in species composition in Expt 4, compared with all the other experiments (Calanus hyperboreus $50 \%$ here and $<20 \%$ elsewhere). This does not seem very likely, but the possibility that different copepod species process pigments differently should be investigated further in the future.

\section{CONCLUSIONS}

Close to $100 \%$ of ingested chlorophyll a and chlorophyll $c$ did not survive passage through the guts of Calanus sp. grazing on diatoms. Virtually no phaeophorbide a or phaeophytin a were produced, but 
instead their pyrolised derivatives, apparently along with a pyrolised derivative of phaeoporphyrin $c$. Of the carotenoids, fucoxanthin was completely broken down during digestion, although it may have been converted to an observable, but unidentified, product. Some proportion of diadinoxanthin was sometimes transferred to faecal pellets intact.

Chlorophyll a, chlorophyll $c$ and diadinoxanthin were partially destroyed during gut passage (i.e. could not be accounted for in known breakdown products). The extent of destruction for each of the 3 was different, but they varied in parallel. The degree of chlorophyll a destruction was always lowest and it varied with previous feeding history of the copepods, as found elsewhere (Penry \& Frost 1991, Head 1992). When the degree of chlorophyll a destruction was relatively low, pyrophaeophorbide a and pyrophaeophytin a were the only breakdown products. When it was relatively high, however, additional unidentified breakdown products were formed.

Acknowledgements. The authors thank Drs R. J. Conover and S. Roy for their comments during the preparation of this manuscript.

\section{LITERATURE CITED}

Bathmann, U., Liebezeit, G. (1986). Chlorophyll in copepod faecal pellets: changes in pellet numbers and pigment content during a declining Baltic spring bloom. P.S.Z.N. I: Mar. Ecol. 7: 59-73

Bidigare, R. R., Kennicutt, M. C., Brooks, J. M. (1985). Raluel determination of chlorophylls and their degradataun products by high-performance liquid chromatography. Limnol. Oceanogr. 30: 432-435

Conover, R. J., Durvasula, R., Roy, S., Wang, R. (1986). Probable loss of chlorophyll-derived pigments during passage through the gut of zooplankton, and some of the consequences. Limnol. Oceanogr. 31. 878-887

Currie, R. I. (1962). Pigments in zooplankton feces. Nature 193: $956-957$

Daley, R. J. (1973). Experimental characterization of lacustrine chlorophyll diagenesis. II. Bacterial, viral and herbivore grazing. Arch. Hydrobiol. 72: 409-439

Gieskes, W W. C., Kraay, G. W. (1989). Estimating the carbon-specific growth rate of the major algal species groups in eastern Indonesian waters by $14 \mathrm{C}$ labeling of taxon-specific carotenoids. Deep Sea Res. 36: 1.127-1139

Head, E. J. H. (1988). Copepod feeding behaviour and the measurement of grazing rates in vivo and in vitro. In: Boxshall, G. A., Schminke. H. K. (eds.) Biology of copepods. Hydrobiologia 167/168: 31-41

Head, E. J. H. (1992). Gut pigment accumulation and destruc-

This article was submitted to the editor tion by arctic copepods in vitro and in situ. Mar. Biol. 112 . $583-592$

Head, E. J. H., Horne, E. P. W. (1992). Pigment transformation and vertical flux in an area of convergence in the north Atlantic. Deep Sea Res. (in press)

Helling, G. R., Baars, M. A. (1985). Changes of the concentrations of chlorophyll and phaeopigment in grazing experiments. Hydrobiol. Bull. 19: 41-48

Holm-Hansen, O., Lorenzen, C. J, Holmes, R. W., Strickland, J. D. H. (1965). Fluorometric determination of chlorophyll. J. Cons. perm. int. Explor. Mer 30: 3-15

Jeffrey, S. W., Hallegraeff, G. M. (1987). Chlorophyllase distribution in ten classes of phytoplankton: a problem for chlorophyll analysis. Mar. Ecol. Prog. Ser. 35: 293-304

Kleppel, G. S., Frazel, D., Pieper, R. E., Holliday, D. V. (1988). Natural diets of zooplankton off southern California. Mar. Ecol. Prog. Ser. 49: 231-241

Kleppel, G. S., Holliday, D. V., Pieper, R. E. (1991). Trophic interactions between copepods and microplankton: a question about the role of diatoms. Limnol. Oceanogr. 36: $172-178$

Lopez, M. D. G., Huntley, M. E., Sykes, P. F. (1988). Pigment destruction by Calanus pacificus: impact on the estimation of water column fluxes. J. Plankton Res. 4: 715-734

Mantoura, R. F. C., Llewellyn, C. A. (1983). The rapid determination of algal chlorophyll and carotenoid pigments and their breakdown products in natural waters by reversephase high-pressure liquid chromatography. Analyt. Chim. Acta 151: 297-314

Nelson, J R. (1989). Phytoplankton pigments in macrozooplankton feces: variability in carotenoid alterations. Mar. Ecol. Prog. Ser. 52: 129-144

Penry, D. L., Frost, B. W. (1991). Chlorophyll a degradation by Calanus pacificus: Dependence on ingestion rate and digestive acclimation to food resources. Limnol. Oceanogr. 36: $147-159$

Rowan, K. S. (1989a). Chlorophylls and derivatives. In: Photosynthetic pigments of algae. Cambridge Univ. Press, Cambridge, p. 65-111

Rowan, K. S. (1989b). The carotenoids. In: Photosynthetic pigments of algae. Cambridge Univ. Press, Cambridge, p. $112-164$

Roy, S. (1989). HPLC-measured chlorophyll-type pigments during a phytoplankton spring bloom in Bedford Basin (Canada). Mar. Ecol. Prog. Ser. 55: 279-290

Roy, S., Harris, R. P., Poulet, S. A. (1989). Inefficient feeding by Calanus helgolandicus and Temora longicornis on Coscinodiscus wailesii: quantitative estimation using chlorophyll-type pigments and effects on dissolved free amino acids. Mar. Ecol. Prog. Ser. 52: 145-153

Roy, S., Poulet, S.A. (1990). Laboratory study of the chemical composition of aging copepod fecal material. J. exp. mar Biol. Ecol. 135: 3-18

Vernet, M., Lorenzen, C.J. (1987). The relative abundance of pheophorbide a and pheophytin a in temperate marine waters. Limnol. Oceanogr. 32: 352-358

Wright, S. W., Shearer, J. D. (1984). Rapid extraction and high-performance liquid chromatography of chlorophylls and carotenoids from marine phytoplankton. J Chromatogr. 294: 281-285

Manuscript first received: April 30, 1992

Revised version accepted: August 11, 1992 